\title{
Impact of Die Materials on the Effect of New Polymer Processing Aids for Sharkskin Properties
}

\author{
Seyed Pooyan Sajjadi \\ Polymertechnik/Polymerphysik, Technische Universit at Berlin, Berlin, Germany \\ Email: S.Pooyan@Sajjadi.me
}

How to cite this paper: Sajjadi, S.P. (2016) Impact of Die Materials on the Effect of New Polymer Processing Aids for Sharkskin Properties. Journal of Materials Science ana Chemical Engineering, 4, 17-27. http://dx.doi.org/10.4236/msce.2016.49002

Received: December 11, 2015

Accepted: September 4, 2016

Published: September 7, 2016

Copyright $\odot 2016$ by author and Scientific Research Publishing Inc. This work is licensed under the Creative Commons Attribution International License (CC BY 4.0).

http://creativecommons.org/licenses/by/4.0/

\begin{abstract}
Flows of polymeric liquids undergo instabilities whose origins are quite different from those of Newtonian flows, due to their elastic character and the complexity of the fluid/solid boundary condition. One of these instabilities is well known as "sharkskin" which damages the surface appearance and properties of polymer extrudate while processing in blowmolding or piping, while it can be suppressed by employing various methods including coating the die surface and/or adding Polymer Processing Aid's (PPA) to the polymer. In this article, the effect of various die materials on the properties of Polyethylene glycol (PEG) as a new type of PPA for suppressing the sharkskin phenomenon has been studied.
\end{abstract}

\section{Keywords}

Polymer Processing Aids (PPA), PEG, Sharkskin, Extrusion Instabilities

\section{Introduction}

In contrast to Newtonian fluids, polymer melts are viscoelastic. So fluid mechanics of polymers is nonlinear even in the absence of inertia, varies from one polymer to another [1]. Also the no-slip condition may not be valid for polymer/solid interface. This may cause so many instabilities to happen while processing the polymers, namely a melt fracture phenomenon called as "sharkskin" because of its morphology; "a surface roughness with a typical largest length scale of about $100 \mu \mathrm{m}$ leading to a matte appearance and rough texture that is undesirable for many practical applications ..." [2]. This phenomenon was observed more than fifty years back for the first time [3]. Moreover, this is one of the first instabilities that will occur during the extrusion process after exceeding a certain limit of mean velocity, temperature, shear stress or mass.

Sharkskin effect is not fully understood as yet, though an extensive amount of efforts had put to recognize the real nature of this surface distortion: an extensive review in 
chapter one of Black [4] likewise the works have been done by Petrie and Denn [5], Hatzikiriakos and Migler [6] [7], Ramamuthy [8] Graham [2], Kurtz [9] and Moynihan et al. [10]. They believed that the initiating site for sharkskin is the die exit area. Hill et al. [11] showed that there is a strong relation between adhesive failure and melt fracture. Recently based on their experimental data and theoretical ideas about the behavior of polymer chains adsorbed from a melt onto a solid surface, Sajjadi and Wagner [12][14] proposed a theory of what may happen in reality [14]. To suppress sharkskin effect, many techniques and additives (PPAs) were suggested and used, including but not limited to use the fluorinated materials as PPA [15], improving the die material [16] or even to coat the die with various mineral substances, polymers and rubbers [9], thermoplastic elastomers [12] and finally, a state-of-art PPA, low molecular weight polymers like Silanols and PEG [12] [14]. The older methods of fluorinated materials are not environmentally friendly, though they can effectively suppress the sharkskin.

\section{Extrapolation Length}

There are so many observations which are supporting the idea that the no-slip condition is not valid for flow of various complex fluids including polymer melts and polymeric suspensions, namely Graham [2] and Brochard and de Gennes [17]. Let us call the velocity on the wall as $V_{s}$ (Figure 1).

As it was said before, the origin of sharkskin is from the difference between the velocity profiles of extrudate inside and outside the die, as it has a parabolic profile with the maximum in center and zero at the wall ${ }^{1}$ inside the die, and it will change to a flat profile with an average velocity far outside the die. Therefore, the acceleration of the molten polymer will be the cause of adhesion failure and finally the sharkskin as it was mentioned before. Moreover, exiting the die, the polymer chains will have the opportunity to relax and hence, die swell will occur as well (Figure 2).

The velocity can be written as Equation (1). As it is shown in Figure 1, the velocity at the wall in case of the adhesive failure, can be calculated as:

$$
\begin{gathered}
\dot{\gamma}=\mathrm{d} v / \mathrm{d} y \\
V_{(y=0)}=V_{s}=\dot{\gamma} \cdot b
\end{gathered}
$$

Parameter " $b$ " is called as extrapolation length. For highly viscous entangled long

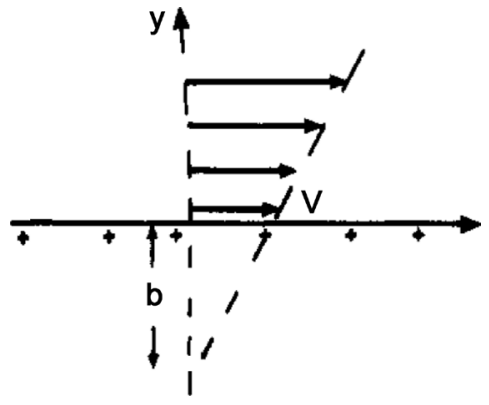

Figure 1. Velocity profile near a slippery solid surface.

\footnotetext{
${ }^{1}$ In case of the absence of the wall slip effect, otherwise, $V_{s}$ is the velocity at the wall.
} 


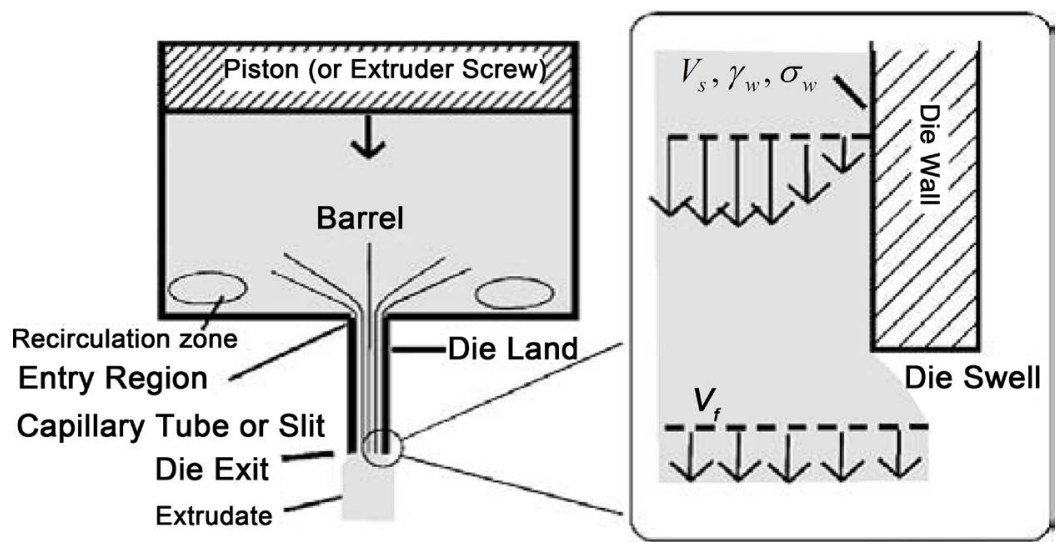

Figure 2. Die swell of polymer, change in velocity profile.

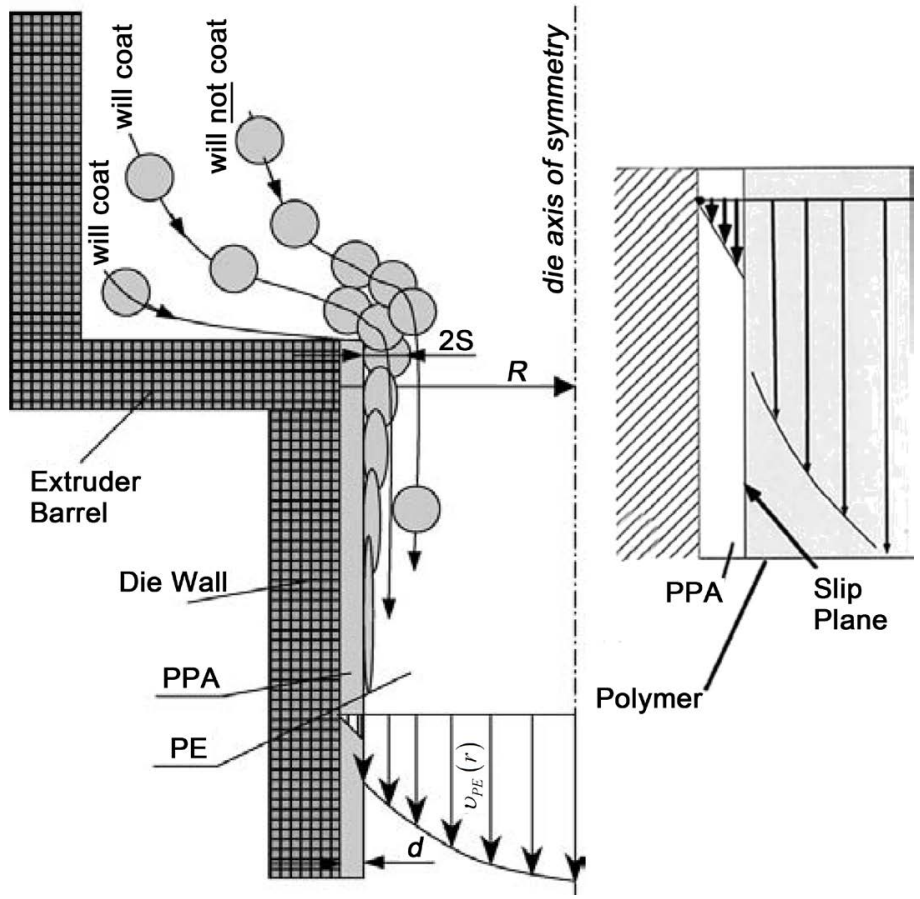

Figure 3. Effect of PPA on molten polymer flow regime [6].

chains it can reach as big as $100 \mu \mathrm{m}$ [18] and this is the case of our long chain Linear Low density Poly Ethylene (LLDPE)macro molecule. It is recognized that the dynamics of the behavior of the macromolecules at the wall, their adsorption, and disentanglement from each other and from the wall, all play significant roles during shearing and flow. There is some evidence that wall slip will occur on the bases of adhesive failure mechanism [19]. The effect of PPA on the flow regime is sketched in Figure 3. The formation of a new layer of PPA will help to increase the wall slip in the exit land area, and it will increase the velocity at the wall, causing the molten polymer to slip at the wall and as result of that the shark skin is suppressed. Therefore, the issue of wall slip is of a great importance in the characterization of the systems of molten polymers in presence of PPAs. As we have dedicated our efforts in this article to characterize the in- 
fluence of die material on the properties of the LLDPE with cured PEG, quantative and/or qualitative measuring of extrapolation length parameter, as well as other important parameters like pressure and mechanical properties of polymer will be our main task in the following chapter.

\section{Experimental}

The low linear density polyethylene that is used is LLDPE $1201 \mathrm{XV}$ from ExxonMobil Chemical (Houston, Texas) [20]. This product has no polymer processing aids inside, moreover the overall amount of all additives is low; hence it might be used as the virgin LLDPE. It has a Melt Flow Index (MFI) Value of $0.7 \mathrm{~g} / 10 \mathrm{~min}$, melting point is $123^{\circ} \mathrm{C}$ and density is $0.925 \mathrm{~g} / \mathrm{cm}^{3}$. Small amount of PPA can suppress the sharkskin, so the dosage of additive decided to be 500 ppmand $1000 \mathrm{ppm}$. The ingredients that are used as Polymer Processing Aids (PPAs) additives are as follows;

1) PPA I: Polyethylene glycol (PEG) with the molecular weight of $20,000 \mathrm{Da}$, can react with the acid boric and borate and will result in a viscoelastic material with three dimensional network (covalent bonds), which can be used as a novel PPA. It is recommended to heat the PEG and boric acid up to $140^{\circ} \mathrm{C}$ and mix them afterward [12].

2) PPA II: Elastomer PPA which is Elastollan ${ }^{\text {Tw }}$ from Elastogran $\mathrm{GmbH}$ (Lemförde, Germany) [22].

3) PPA III: Viton Free Flow ${ }^{\text {tw }} \mathrm{Z} 100$ is from DuPont (Rockville, MD) [21].

4) PPA IV: Dynamar ${ }^{\mathrm{Tm}}$ FX 5922 from Dyneon (3 M, St. Paul, MN) [23].

A two heating zone Göttfert extruder machine was equipped with temperature and pressure sensors at the die exit. There were implemented inside a special specimen from tool steel, heated up to the same temperature as the heating zone and has the temperature and pressure plug-ins sensors (Figure 4). We employed a fixed flow rate

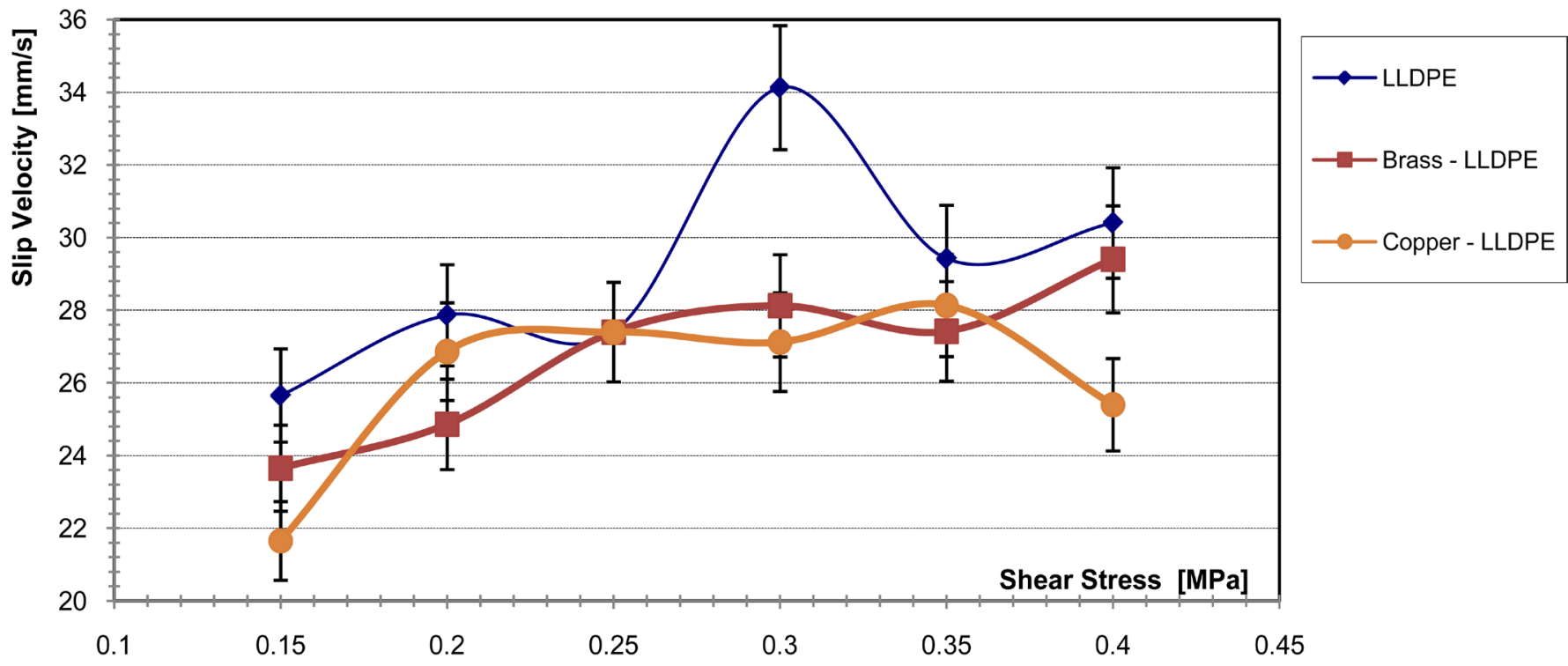

Figure 4. Effect of die material on slip velocity for pure LLDPE. 
Capillary Rheometry with the barrel length of $12 \mathrm{~cm}$ and the speed set at 30 to 1100 [1/s]. Mooney Experiment [24] is one of the ways to estimate the slip velocity at the die wall which has been done with three different die materials and 4 different PPAs on the LLDPE at the fix condition of $180^{\circ} \mathrm{C}$ temperature. 6 different die sizes of steel die are reported in Appendix A. Also a Leica-flex from the Leica ${ }^{\mathrm{Tw}}$ [25] light microscope is used at $6.4 \times, 16 \times$ and $40 \times$ zoom to determine the size and the shape of irregularities on the polymer skin. To determine the particle distribution of PEG PPA, the SEM microscopy method is employed. The zooms that are used are 30×, 50×, 100×, 150×, 500×, 1000×.

Adding the PPA will result in decreasing the pressure of outgoing extrudate, this phenomenon can be caused by various parameters. The pressure increases with the increase of rotation speed of machine, but the behaviour after the sharkskin onset can interpret the interaction of melt and die, hence it was decided to study this function more. Consider that this pressure drop can be a function of at least 5 important elements: speed of rotation, temperature of melt polymer, die material, type of additive and additive concentration. Intended to make this complexity easier to understand, initially the 2 parameters speed of extruder and temperature of heating zones were kept constant, while rest of parameters were changed. The pressure of 180 bar was selected to be the starting point for the performing of the rest of the experiments as it was the highest safe pressure available and speed rotation of $25 \mathrm{rpm}$ was selected to be the speed correlating the chosen pressure, with different PPAs, various amounts of PPAs and with 2 types of die materials with the same dimension. (Diameter: $1.4 \mathrm{~mm}$, length: 14.5 $\mathrm{mm}$ ) The temperature was kept at $180^{\circ} \mathrm{C}$ for all the experiments. Afterward, the PPA was added gradually, causing the decrease of pressure. This drop of pressure could be measured easily, moreover the time that is needed to reach a plateau after adding the PPA is also observable.

\section{Results and Discussions}

Initially the onset of sharkskin was measured with the pure LLDPE and two different die materials; steel and brass. Hardly any difference was observed between the two different die materials, as for both of them onset of sharkskin was round 140 bar and 10 RPM the speed of extruder. Also the same pressure drop of 173 Bars from the initial 180 Bars pressure were recorded during adding of various concentrations of PPA II with steel and brass die materials. It obviously contradicts the result from other researches e.g. Ramamurthy et al. [8] which was showing that changing the die material will change the sharkskin onset considerably. As an example, brass is supposed to reduce the shark skin onset. To our surprise, even in the capillary rheometer no changes have been made by different materials. The shear rates value for sharkskin onset in pure LLDPE extrusion with different die materials in capillary rheometer is reported 40 [1/s] for steel, $44[1 / \mathrm{s}]$ for brass and $42[1 / \mathrm{s}]$ for copper die. This result is to some extend odd as previous articles claimed verse. This proves that the effect of die materials is of no great value in the sharkskin phenomenon and it should not take in consideration. The idea behind was that because of the predicted effect of die material on the "b" value, 
same thing shall be observed in sharkskin, which was not true. Neither the extruder nor the capillary show any change. The slip velocity at the wall could also play an important role on the final conclusion of this topic. Mooney Experiment [24] for steel, brass and copper showed the same wall slip velocities with pure LLDPE at $180^{\circ} \mathrm{C}$ as it is shown in Figure 4. The only difference is the slip velocity at $0.3 \mathrm{MPa}$ and the slip velocity for steel die is rather odd, while the copper also showing falling at very low and very high shear stresses. But this much of tolerance is negligible as it is even less than $5 \%$. This solved the puzzle of effect of die material on sharkskin as really it has no effect on this phenomenon. The result for sure is on the research level and to scale it up to huge industrial extruders with different additives and conditions, one should be really careful, as the LLDPE that is used here is without any special additive for sharkskin. The results from frequency of sharkskin and size of it took the same side. Some pictures from the ruptured surface were taken by light microscope (Figure 5). The frequency of peaks on the surface with sharkskin was checked on the same rotation speed and pressure, whether with using different die materials it will change. Since the mass flow rate was just the same (pressure and speed of rotation were the same as onset of sharkskin), the speed of outcome were the same in both dies. The average distance between the peaks were averagely $310 \mu \mathrm{m}$ for both die materials. It might show the die material will NOT affect the severity of the sharkskin by size or frequency.

Figure 5 is dedicated to show the effect of adding PEG as a PPA for brass and copper die. If we compare these results with Figure 4, one can see the same pattern of behavior as the PEG added portion will show lower wall slip velocity, but the difference is slightly less comparing to steel die, means that PEG as a PPA interact with brass and copper die in a way that it will decrease the slip velocity less than the case of steel die. Only thing,

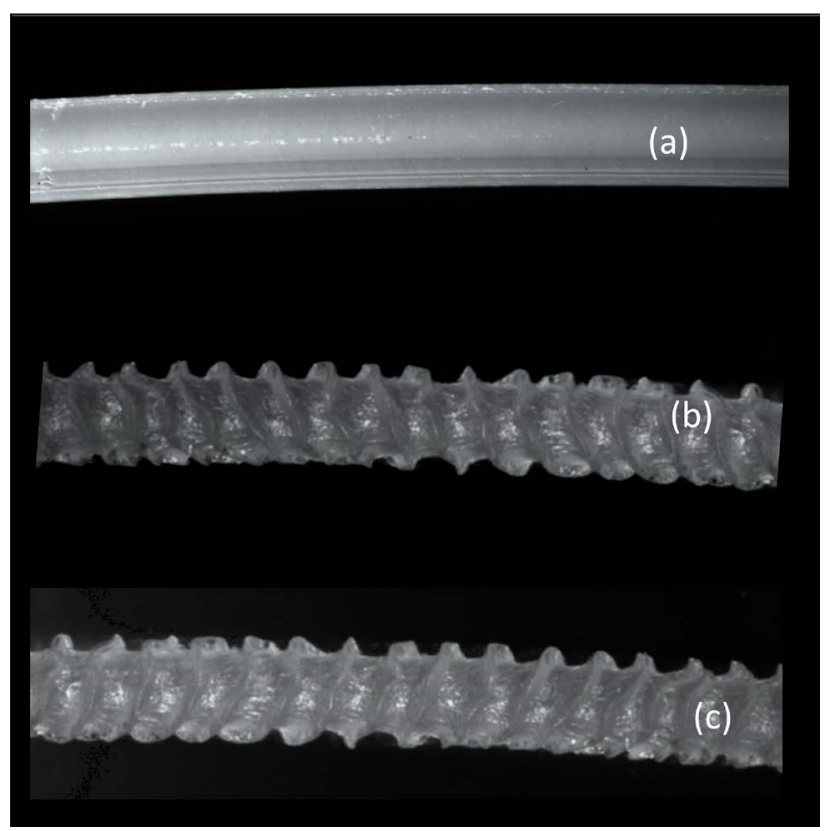

Figure 5. Light microscope image from sharkskin effect appearance of Pure LLDPE with different dies: (a) Without shark skin; (b) Shark skin in brass die; (c) Shark skin in steel die. 
at the very beginning and end of the graph, a decreasing deviation from ideal case is observable for pure LLDPE.

Figure 6 shows that PEG and fluorinated PPA Viton are showing same pattern of behavior, while E685 which is the elastomer PPA is showing increase of slip velocity on the die wall. This is for sure has the root in the nature of these different PPAs, but shows clearly that PEG has the same attitude as fluorinated PPAs. Note that for reducing the complexity of the graph, the result of Dynamar is not included in this graph, as it has exactly the same pattern as the other fluorinated PPA, Viton has. Interesting enough, the sharkskin was suppressed in all the cases. We knew about the sharkskin suppressing effect of Dynamar and Viton, and the new state of art elastomer additive was also pretty good in delaying the onset of sharkskin. PEG also shows very good result at this point. While the pure LLDPE has the sharkskin onset of 40 [1/s], adding $0.1 \%$ of PPA III and IV increase this to the higher amount of 56 [1/s]. Adding PEG has increased this to even higher degree of $65[1 / \mathrm{s}]$ and PPA II has the highest amount of 71 [1/s]. But the Figure 7 shows clearly that the approach to suppress the sharkskin should

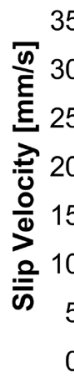

35
30
25
20
20
15
10
5
5
0
0
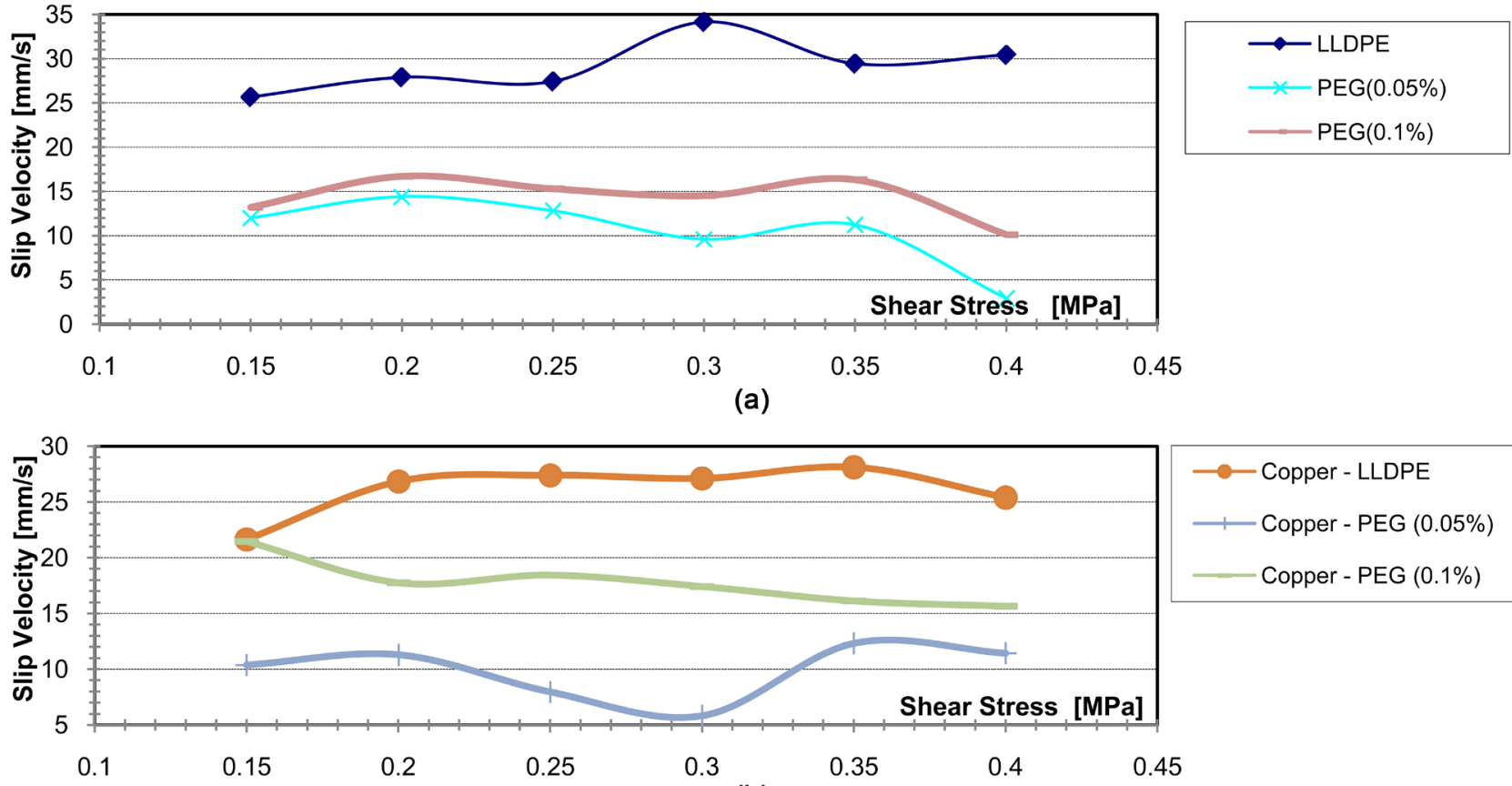

(a)

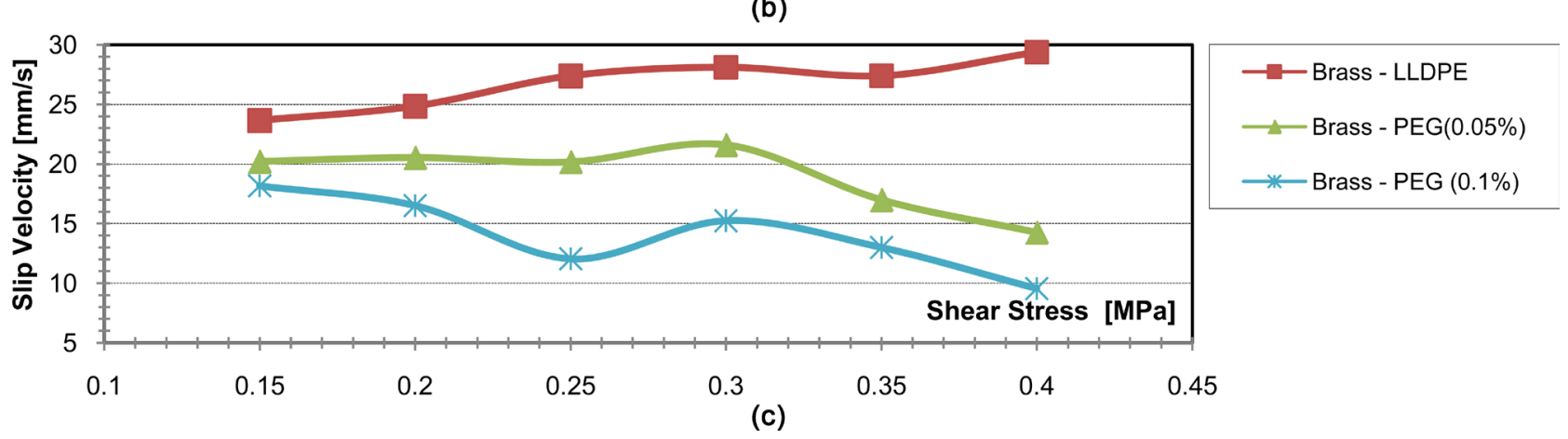

Figure 6. Effect of different amount of PPA Ion slip velocity for brass and copper die. 


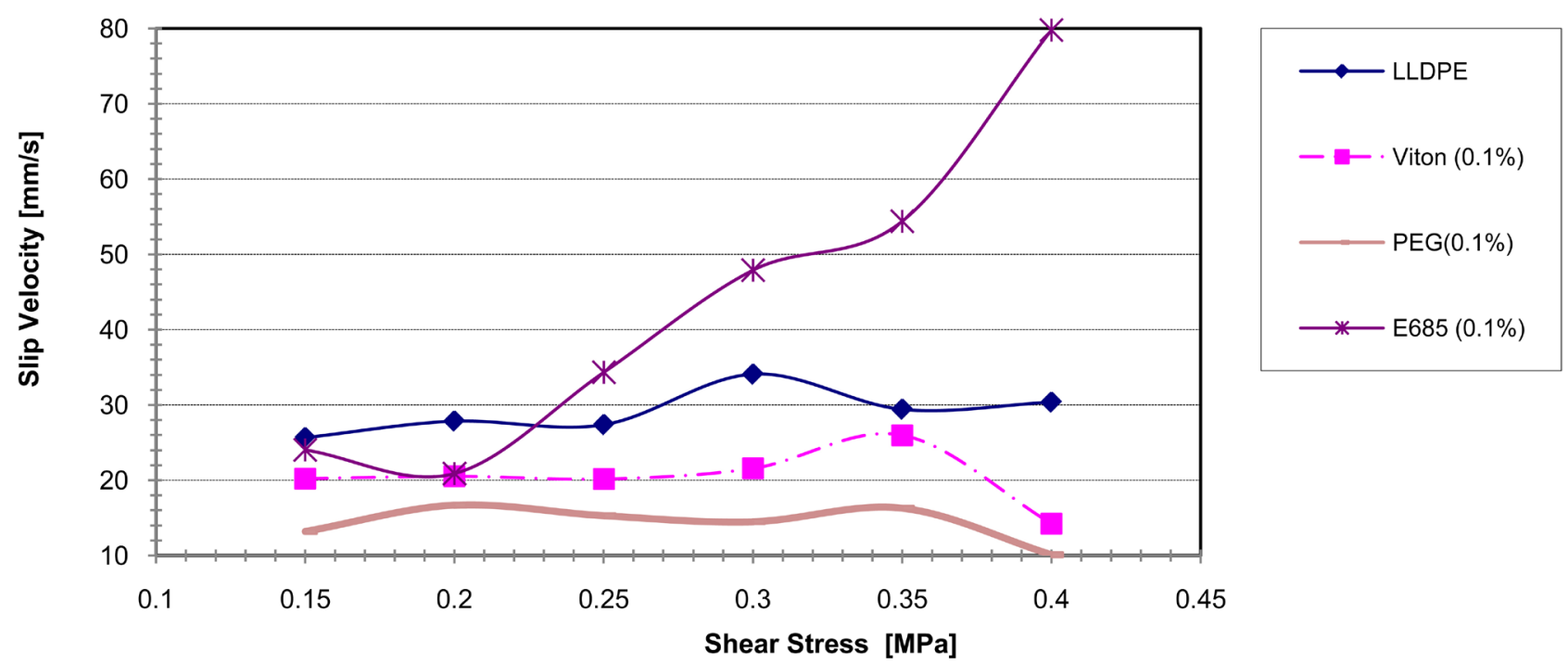

Figure 7. Effect of adding same amount of different PPAs to pure LLDPE on slip velocity of steel die.

be absolutely different. Different slip velocity at the wall shall make a great difference, but it is not. The difference is coming from the point that if rethink of mechanism of sharkskin, there is a layer of PPA which will coat the die inner surface or die wall, and it depends on where we call it the die wall in rheometer, whether the PEG coating or Elastogran coating, or real steel die wall, we will see different slip velocities. That is how different PPAs will suppress the sharkskin with different slip velocity at the wall. What is the important point here is the fact that PEG is following the same pattern as Viton and Dynamar and rest is the by-product of this article. Moreover, comparing the SEM shots from Elastogran with PEG, e.g., compare Figure 8(a) with the Figure 8(b), shows that PEG mixture with LLDPE is homogenous mixture, while Elastogran make an obviously heterogeneous melt. If the mixture is at least to some extend homogenous, then there is no question of migrating to make a layer as it is already presenting at the place. As it is, the black spots are most probably a burning area because of contact for a long time with die wall. Another interesting aspect is the very smooth surface of PEG blended LLDPE, which even with great zooms shows no special artifact. PEG doing its sharkskin suppressing job very well and that is how the common waves causing by sharkskin are vanished from the canvas.

\section{Conclusions}

About 50 years back, Bagley et al. [3] was one of the pioneers to search for the origin of a defect on the surface of polyolefins specially LLDPE and HDPE, which was called as "sharkskin". Although that are various mechanism suggested as a cause of this phenomena, the real cause of this melt fracture is yet not fully understood, but as a hypothesis, the Kulikov and Wagner [10]-[12] seems to be realistic. As a novel way to suppress sharkskin, PEG cured with boric acid, can be added in small portions and the sharkskin vanishes [12]. The PEG migrates to the wall of die and causes the wall slip of extrudate and hence suppress of sharkskin. Therefore, as the sharkskin is dependent to 


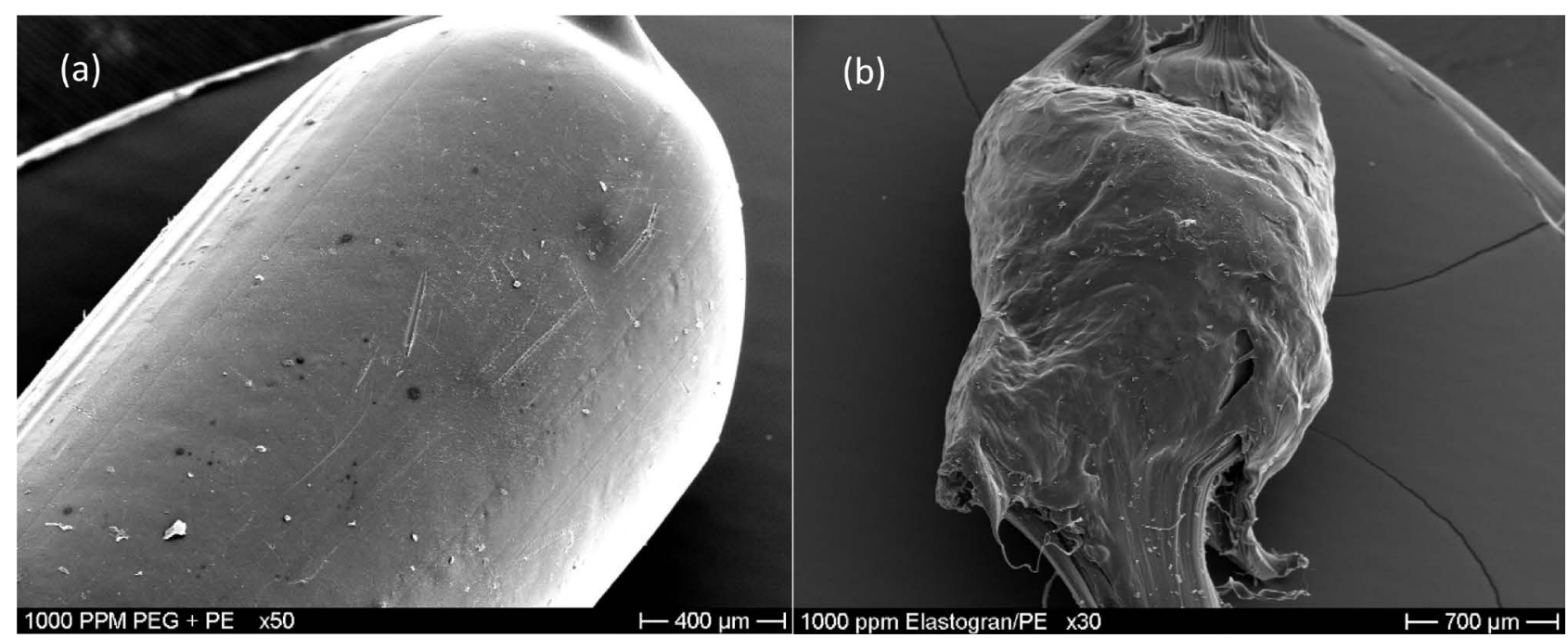

Figure 8. SEM pictures from LLDPE matrix with PEG (PPA I) (a) and Elastogran (PPA II) (b) as additives.

wall slip by nature, in this article, we will try to characterize the properties and decencies of PEG added extrudate of LLDPE to the die material. Study with capillary rheometer made a way to observe the real natural dependency of sharkskin to die material. In this case, the wall slip velocity of LLDPE in presence of various PPAs and with different die materials were examined and compared. Moreover, the onset of sharkskin with different die materials was recorded. To our surprise, even the capillary rheometer studies supported the result of extruder machine about die material. Moreover, the frequency and size of sharkskin was controlled if it shows any change while changing the die material.

All in all, the conclusion out of three different methods of observing the effect of die material on sharkskin is that it does not play an important role in this phenomenon. PEG anyway suppressed sharkskin and delayed the sharkskin onset in the capillary rheometer. Anyway, the pattern of behavior of PEG is different from Elastomeric PPAs and it is so reminding of Fluoropolymer e.g. Viton.

\section{Acknowledgements}

I highly appreciate kind help rendered by Prof. M.H. Wagner and Dr. Ing. Tobias Himmel from Polymer department of Technical University, Berlin.

\section{References}

[1] Venet, C. and Vergnes, B. (1997) Experimental Characterization of Sharkskin Inpolyethylene. Journal of Rheology, 41, 873-892. http://dx.doi.org/10.1122/1.550837

[2] Graham, M.D. (1999) The Sharkskin Instability of Polymer Melt Flows. Chaos, 9, 154-163. http://dx.doi.org/10.1063/1.166386

[3] Bagely, E.B., Cabot, I.M. and West, D.C. (1958) Discontinuity in Flow Curve of Polyethylene. Journal of Applied Physics, 29, 109-110. http://dx.doi.org/10.1063/1.1722930

[4] Black, W.B. (2000) Wall Slip and Boundary Effects in Polymer Shear Flows. Ph.D. Thesis, University of Wisconsin, Madison. 
[5] Petrie, C.J.S. and Denn, M.M. (1976) Instabilities in Polymer Processing. A.I.Ch.E Journal, 22, 209.

[6] Hatzikiriakos, S.G. and Migler, K.B. (2005) Polymer Processing Instabilities, Control and Understanding.

[7] Blatz, P.S. (1964) US Patent 3125547.

[8] Ramamurthy, A.V. (1986) Wall Slip in Viscous Fluids and Influences of Materials of Construction. Journal of Rheology, 30, 337-357. http://dx.doi.org/10.1122/1.549852

[9] Kulikov, O. and Hornung, K. (2004) Simple Way to Suppress Surface Defects in the Processing of Polyethylene. Journal of Non-Newtonian Fluid Mechanics, 124, 103-114. http://dx.doi.org/10.1016/j.jnnfm.2004.07.009

[10] Moynihan, R.H., Baird, D.G. and Ramanathan, R. (1990) Additional Observations on the Surface Melt Fracture Behaviour of the Linear Low Density Polyethylene. Journal of NonNewtonian Fluid Mechanics, 36, 255-263. http://dx.doi.org/10.1016/0377-0257(90)85012-N

[11] Kulikov, O., Hornung, K. and Wagner, M. (2007) Silanols Cured by Borates as Lubricants in Extrusion of LLDPE. Impact of Elasticity of the Lubricant on Sliding Friction. Journal of Rheologica Acta, 46, 741-754. http://dx.doi.org/10.1007/s00397-007-0171-1

[12] Sajjadi, S.P. (2009) Impact of Die Materials on the Effect of New Polymer Processing Aids for Sharkskin Properties. M.Sc. Thesis, Technical University of Berlin, Berlin.

[13] Cogswell, F.N. (1977) Stretching Flow Instabilities at the Exits of Extrusion Dies. Journal of Non-Newtonian Fluid Mechanics, 2, 37-47. http://dx.doi.org/10.1016/0377-0257(77)80031-1

[14] Tramblay, B. (1991) Sharkskin Defects of Polymer Melts: The Role of Cohesion and Adhesion. Journal of Rheology, 35, 985-998. http://dx.doi.org/10.1122/1.550177

[15] Kulikov, O. (2005) Novel Processing Aids for Extrusion of Polyethylene. Journal of Vinyl and Additive Technology, 127-131.

[16] Kalika, D.S. and Denn, M.M. (1987) Wall Slip and Extrudate Distortion in Linear LowDensity Polyethylene. Journal of Rheology, 31, 815-834. http://dx.doi.org/10.1122/1.549942

[17] Hill, D.A., Hasegawa, T. and Denn, M.M. (1990) On the Apparent Relation between Adhesive Failure and Melt Fracture. Journal of Rheology, 34, 891-918. http://dx.doi.org/10.1122/1.550105

[18] Brochard, F. and de Gennes, P.G. (1992) Shear-Dependent Slippage at a Polymer/Solid Interaface. Langmuir, 8, 3033-3037. http://dx.doi.org/10.1021/la00048a030

[19] Olgun, U. and Kalyon, D.M. (2005) Use of Molecular Dynamics to Investigate Polymer Melt-Metal Wall Interactions. Journal of Polymer, 46, 9423-9433. http://dx.doi.org/10.1016/j.polymer.2005.07.042

[20] http://www.exxonmobill.com/chemicals

[21] http://www.wacker.com

[22] http://www.dupont-dow.com

[23] http://www.3m.com

[24] Mooney, M. (1931) Explicit Formulas for Slip and Fluidity. Journal of Rheology, 2, 210-222. http://dx.doi.org/10.1122/1.2116364

[25] http://www.leica-microsystems.com/ 


\section{Nomenclature}

PPA: Polymer Processing Aid;

LLDPE: Low Linear Density Poly Ethylene;

PEG: Poly Ethylene Glycol;

MFI: Melt Flow Index;

$\dot{\gamma}_{A}$ : Apparent Shear Rate Based on the Volumetric Flow Rate;

$V_{\dot{s}}$ : Velocity at the Wall.

\section{Appendix A}

\begin{tabular}{cccccc}
\hline \multicolumn{5}{c}{ Die diameter and die length for steel, brass and copper die } \\
\hline Die material & Die diameter $[\mathrm{mm}]$ & Die length $[\mathrm{mm}]$ & L/D & $1 / \mathrm{D}[1 / \mathrm{mm}]$ & $1 / \mathrm{R}[1 / \mathrm{mm}]$ \\
\hline 0.445 & 4.44 & 9.98 & 2.25 & 4.49 \\
& 0.675 & 6.75 & 10.00 & 1.48 & 2.96 \\
Steel & 0.853 & 8.524 & 9.99 & 1.17 & 2.34 \\
& 1.167 & 11.67 & 10.00 & 0.86 & 1.71 \\
& 1.274 & 12.75 & 10.01 & 0.78 & 1.57 \\
& 1.467 & 14.67 & 10.00 & 0.68 & 1.36 \\
\hline \multirow{3}{*}{ Brass } & 0.8 & 7.95 & 9.937 & 1.25 & 2.5 \\
& 0.62 & 6.1 & 9.838 & 1.62 & 3.22 \\
& 1.18 & 11.9 & 9.406 & 0.85 & 1.69 \\
& 1.467 & 14.67 & 10.00 & 0.68 & 1.36 \\
\hline 0.62 & 5.9 & 9.516 & 1.61 & 3.22 \\
& 0.8 & 7.9 & 9.875 & 1.25 & 2.5 \\
& 1.19 & 11.85 & 9.957 & 0.84 & 1.68 \\
\hline
\end{tabular}


Submit or recommend next manuscript to SCIRP and we will provide best service for you:

Accepting pre-submission inquiries through Email, Facebook, LinkedIn, Twitter, etc. A wide selection of journals (inclusive of 9 subjects, more than 200 journals)

Providing 24-hour high-quality service

User-friendly online submission system

Fair and swift peer-review system

Efficient typesetting and proofreading procedure

Display of the result of downloads and visits, as well as the number of cited articles

Maximum dissemination of your research work

Submit your manuscript at: http://papersubmission.scirp.org/ 